\title{
The applicability of soil flushing technology in a metallurgical plant
}

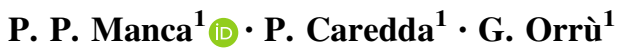

Received: 18 July 2017/Revised: 1 December 2017/Accepted: 3 January 2018/Published online: 17 January 2018

(C) The Author(s) 2018. This article is an open access publication

\begin{abstract}
Soil flushing technology is an 'in situ' remediation technique involving the injection of a liquid solution. Applications of the soil flushing technique depend on the leachability of the pollutants and the environmental compatibility and total volumes of the solutions used. Therefore, experiments should consider these aspects by simulating the real phenomenon and using the most suitable reagents for the leachability of the different mineralogical forms present. Thirtyone laboratory tests were carried out (in batch and becker) to the complete exhaustion of the leaching capacity according to $\mathrm{pH}$ measurements. The reaction kinetics were studied by producing more than 300 solution samples during which the principal heavy metal concentrations, $\mathrm{pH}$ and Eh were measured. Leaching solutions containing various concentrations of hydrochloric, sulphuric, nitric and acetic acids were used. Mercury was leached using potassium iodide and acetic acid ( $\mathrm{pH}$ 2). Analytes such as arsenic, cadmium, mercury, lead, selenium and zinc proved to be leachable in the investigated soil layer. However, high removal efficiencies could be obtained using different typological solutions, concentrations and volumes. The paper discusses the applicability of the soil flushing technique for different heavy metal contents and $\mathrm{pH}$ conditions of the flushing solution.
\end{abstract}

Keywords Soil flushing $\cdot$ Metallurgical plant $\cdot$ Heavy metal leaching

\section{Introduction}

Soil flushing is the extraction of contaminants from the soil using water or other suitable aqueous solutions. The technique can also promote mobility and migration of metals by solubilizing the contaminants so that they can be extracted (EPA 1991).

In the environment, heavy metals are generally more persistent than organic contaminants such as pesticides or petroleum byproducts and they can become mobile in soils depending on soil $\mathrm{pH}$ and their speciation (Hashim et al. 2011).

\section{P. P. Manca}

ppmanca@unica.it

1 DICAAR, Department of Civil Engineering Environmental and Architecture, University of Cagliari, Cagliari, Italy
Generally, in situ technologies are cheaper and safer than ex situ technologies, because excavation is not required; extracting solutions are in fact directly injected into the soil and not mixed in a separate vessel. The flushing fluid is typically water and may contain additives, such as chelating agents, to improve contaminant desorption from the soil matrix (Di Palma et al. 2005).

The current study focuses on soils at a metallurgical plant (Mann 1999; Svab et al. 2009; Navarro and Martinez 2010) that produces $\mathrm{Pb}$ and $\mathrm{Zn}$. The stratigraphy of the experimental site consists of a surface layer that contains contaminated soils up to a depth of $4 \mathrm{~m}$.

The metallurgical plant, still active, is in the industrial area of Sulcis (Sardinia, Italy) and the soil removal technique cannot be applied during its operative life (Desogus and Manca 2013).

Our study reports the results of laboratory tests in order to assess the applicability of Soil Flushing Reclamation 
Technology (Mulligan et al. 2001). Nevertheless, flushing technology is based on the continuous flow of the flushing solution through the contaminated porous material layer. Hence, hydraulic permeability of the polluted matrix is an important limiting factor governing the applicability of the flushing technology (Khan et al. 2004). We conducted a series of laboratory tests to account for the variability due to time of conditioning between the solution and the contaminated soil.

The research was performed in the following steps: (i) selection of the survey area and soil sample formation to be used in laboratory tests; (ii) characterisation of the selected soil sample; (iii) performing batch and Becker tests and (iv) final considerations on the applicability of soil flushing methods to the sampled soil.

\section{Materials and methods}

\subsection{Soil sampling and analysis}

The sample to be subjected to laboratory tests was chosen after investigating the top soil of the industrial plant area up to a depth of $4 \mathrm{~m}$. After discarding the first $1 \mathrm{~m}$ of topsoil, we observed that maximum pollutants occurred between 1 to $2 \mathrm{~m}$ of the top soil (Fig. 1). The elements above the concentration threshold of contamination (CTC) were $\mathrm{As}, \mathrm{Cd}, \mathrm{Hg}, \mathrm{Pb}$, Se and $\mathrm{Zn}$.

The identified soil was characterised based on main components, mineralogical composition and other physicochemical properties.

The particle size composition of soil wt\% (total and $<2 \mathrm{~mm}$ ) is shown in Table 1 . The gravel fraction $(>2 \mathrm{~mm}$ ) was excluded from the leaching tests.

The physical characteristics and organic carbon content of the samples soil are shown in Table 2. The parameters $\mathrm{D}_{50}, \mathrm{D}_{10}$ and $\mathrm{D}_{60}$ represent the intercepts for $50 \%, 10 \%$ and

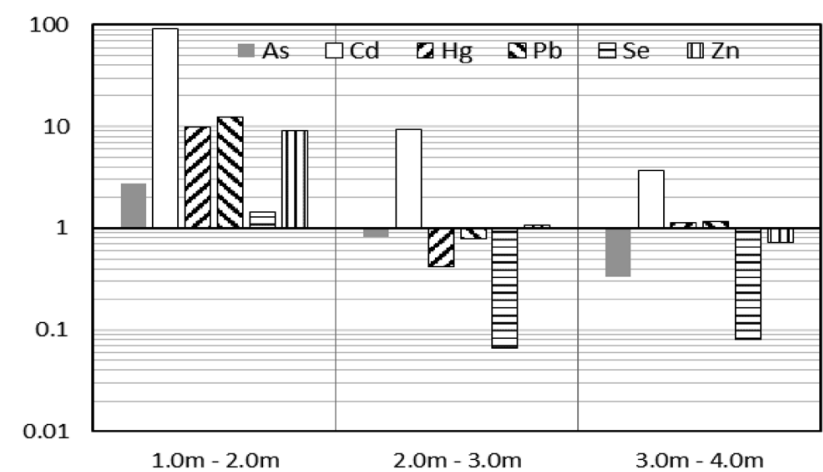

Fig. 1 Histograms of the ratios between concentrations measured and CTC for the three investigated depths
Table 1 Particle size distribution of the sampled soil

\begin{tabular}{llll}
\hline Sample & Size $(\mathrm{mm})$ & wt $\%$ & $<2 \mathrm{~mm} w t \%$ \\
\hline Gravel & $>2$ & 18 & \\
Sand & $0.0625-2$ & 68 & 83 \\
Silt & $0.002-0.0625$ & 7 & 8.5 \\
Clay & $<0.002$ & 7 & 8.5 \\
\hline
\end{tabular}

Table 2 Physical properties

\begin{tabular}{ll}
\hline Properties & Values \\
\hline $\mathrm{pH}$ & 7.9 \\
$\mathrm{D}_{50}(\mathrm{~mm})$ & 0.40 \\
$\mathrm{D}_{10}(\mathrm{~mm})$ & 0.04 \\
$\mathrm{D}_{60}(\mathrm{~mm})$ & 0.50 \\
Moisture content $(\%)$ & 12.5 \\
$\mathrm{k}$ Hazen empirical formula $(\mathrm{m} / \mathrm{s})$ & $1 \times 10^{-6}$ \\
Organic carbon $(\%)$ & 0.10 \\
Soil particle density $\left(\mathrm{g} / \mathrm{cm}^{3}\right)$ & 2.7 \\
\hline
\end{tabular}

$60 \%$ of the cumulative mass, respectively. The hydraulic conductivity $(k)$ from grain size analyses was calculated using the Hazen empirical formula.

We also subjected the sampled soil to mineralogical XRD analysis (JCPDS 1985; Fig. 2) for the determination of the main components and found that it mainly contained quartz, sanidine and plagioclase.

Chemical analyses were performed for the determination of major (Table 3) and minor components (Table 4) and LOI. Table 4 also shows the CTC values in comparison to the values of Italian regulation for industrial sites.

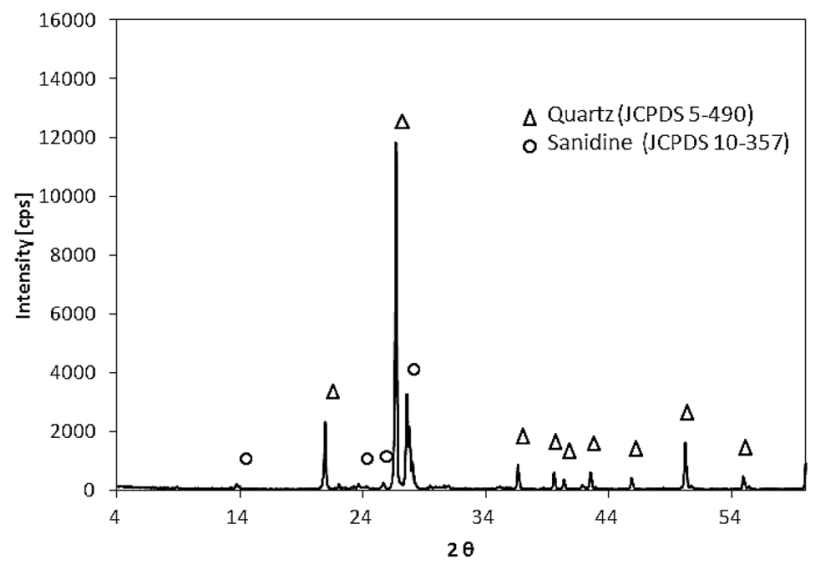

Fig. 2 XRD analysis of the sampled soil 
Table 3 Major oxides in the sampled soil

\begin{tabular}{lc}
\hline Chemical properties & Soil wt $\%$ \\
\hline $\mathrm{Al}_{2} \mathrm{O}_{3}$ & 6.8 \\
$\mathrm{Fe}_{2} \mathrm{O}_{3}$ & 1.8 \\
$\mathrm{MnO}$ & 0.0 \\
$\mathrm{MgO}$ & 0.2 \\
$\mathrm{CaO}$ & 1.7 \\
$\mathrm{~K}_{2} \mathrm{O}$ & 2.5 \\
$\mathrm{Na}_{2} \mathrm{O}$ & 0.1 \\
$\mathrm{TiO}_{2}$ & 0.1 \\
$\mathrm{P}_{2} \mathrm{O}_{5}$ & 0.0 \\
$\mathrm{SiO}_{2}$ & 85.0 \\
$\mathrm{LOI}$ & 1.9 \\
\hline
\end{tabular}

\subsection{Instrumentation}

The solids and solution leachings were analysed using inductively coupled plasma-optical emission spectroscopy (ICP-OES) technique (ICP DV 7000 Optima, PerkinElmer). Concentrations of $\mathrm{Hg}$ were analysed (EPA 1994) using an atomic absorption spectrometer (flow injection automatic mercury system (F.I.M.S. 100, PerkinElmer; $0.01 \mu \mathrm{g} / \mathrm{L}$ detection limit).

In this study, the solution was analysed using the UNI EN 12506: 2004 method, the solids were analysed using the 6010C 2007 EPA method and the EPA regulations 1994 for the determination of $\mathrm{Hg}$. Batch tests were performed in a double-jacketed batch reactor.

Becker tests were carried out in a $300 \mathrm{~cm}^{3}$ container consisting of solid rotation and leach solution using magnetic anchor for a conditioning time of 1, 3,5 and $10 \mathrm{~min}$. After a sedimentation time of $10 \mathrm{~min}$, the supernatant was collected and filtered through a Whatman 42 filter paper. The $\mathrm{pH}$ and Eh of the solution were analysed using Orion 4 and 5 Star, respectively, followed by chemical analysis of the leaching solution. Repeated washing ended when the $\mathrm{pH}$ of the solution reached the initial nominal value. The required total number of washings varied between 15 and 45 due to the differences in the solute used, the $\mathrm{pH}$ of the solution and the conditioning time. The sample volume varied from 200 to $800 \mathrm{~cm}^{3}$. For each sample, the reference volume, $\mathrm{pH}$ and Eh values were recorded. For each test in the reactor, $150 \mathrm{~g}$ of solid was used. Becker tests were performed on $10 \mathrm{~g}$ of solid in a total volume (solid + solution) of $150 \mathrm{~cm}^{3}$.

\subsection{Metal speciation}

The sequential extraction procedure was carried out according to the BCR method (Sahuquillo et al. 2003; Nemati et al. 2011).

The results (Fig. 3) showed that $\mathrm{Cd}$ and $\mathrm{Zn}$ were the most easily leachable elements with high fraction of the

Table 4 Minor chemical elements in the sampled soil

\begin{tabular}{llr}
\hline Elemental concentration & Values $(\mathrm{mg} / \mathrm{kg})$ & Italian legislation CTC for industrial sites \\
\hline $\mathrm{Sb}$ & 25.70 & 30 \\
$\mathrm{As}$ & 136 & 50 \\
$\mathrm{Be}$ & $<1.00$ & 10 \\
$\mathrm{Cd}$ & 1380 & 15 \\
$\mathrm{Co}$ & 3.78 & 250 \\
$\mathrm{Cr}$ & 9.3 & 800 \\
$\mathrm{Cr} \mathrm{VI}$ & $<1.0$ & 15 \\
$\mathrm{Hg}$ & 49.2 & 5 \\
$\mathrm{Ni}$ & 6.0 & 500 \\
$\mathrm{~Pb}$ & 12,200 & 1000 \\
$\mathrm{Cu}$ & 263 & 600 \\
$\mathrm{Se}$ & 21.4 & 15 \\
$\mathrm{Sn}$ & 15.1 & 350 \\
$\mathrm{Tl}$ & 8.1 & 10 \\
$\mathrm{~V}$ & 7.6 & 250 \\
$\mathrm{Zn}$ & 13,600 & 1500 \\
$\mathrm{Total}$ cyanide & $<0.1$ & 100 \\
$\mathrm{Fluoride}$ & 5.94 & 2000 \\
$\mathrm{~S}$ SO4 & 282.00 & \\
\hline
\end{tabular}




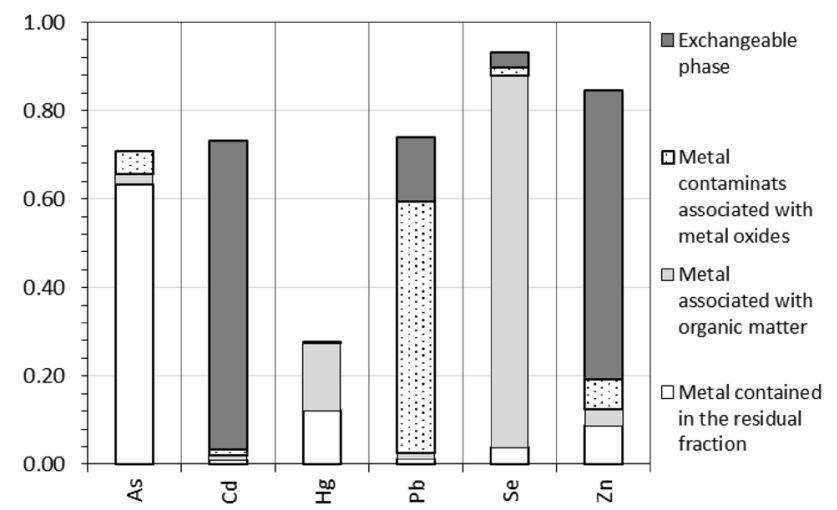

Fig. 3 Fractionation of $\mathrm{As}, \mathrm{Cd}, \mathrm{Hg}, \mathrm{Pb}, \mathrm{Se}$ and $\mathrm{Zn}$ in the contaminated soil

exchangeable phase. Both $\mathrm{Pb}$ and $\mathrm{Se}$ exhibited a low fraction of exchangeable phase. $\mathrm{Pb}$ also had a higher fraction of contaminants associated with metal oxides while Se had the highest fraction of metal associated with organic matter (Fig. 3). As and, in particular, Hg appeared to be hardly leachable (indicated by relatively higher percentage of residual fraction).

\section{Experimental results}

A total of 31 tests were carried out that included 300 specimens of solutions, each analysed for six chemical elements, $\mathrm{pH}$ and Eh.

\subsection{Batch tests}

The results of the tests carried out in the reactor are shown in Fig. 4 (sum of final extraction yield) and 5 (kinetics of the reaction). Preliminary tests with hydrochloric acid (C), sulphuric acid $(\mathrm{S})$ and nitric acid $(\mathrm{N})$ were carried out at a $\mathrm{pH}=2$. The solid/liquid ratio $(\mathrm{S} / \mathrm{L})$ was $1 / 5$. Subsequently, two tests were performed with acetic acid at $\mathrm{S} / \mathrm{L}=1 / 5(\mathrm{~A})$ and $\mathrm{S} / \mathrm{L}=1 / 50(\mathrm{~L})$.

The histogram of Fig. 4 shows the sum of the extraction yield of the six analytes calculated that refer back to the concentrations reported in Table 4.

The values of $\mathrm{Cd}$ and $\mathrm{Zn}$ were always higher than $75 \%$ 80\%; while the As and $\mathrm{Hg}$ concentrations measured were always $<0.5 \mathrm{mg} / \mathrm{kg}$. The best result at a Solid/Liquid $=1 /$ 5 was that obtained using sulphuric acid. With acetic acid, significant values of $\mathrm{Pb}$ (both with $\mathrm{S} / \mathrm{L}=1 / 5$ and $\mathrm{S} / \mathrm{L}=50$ ) could be achieved. Selenium values were significant only with a $\mathrm{S} / \mathrm{L}=50$ ratio. Maximum extraction was obtained within the first $200 \mathrm{~min}$ (Fig. 5; compared to that of 1200 min duration of the $\mathrm{C}-\mathrm{L}$ tests). Maximum extraction yield value of Se reached after 600 min only in the case of test $\mathrm{L}$.

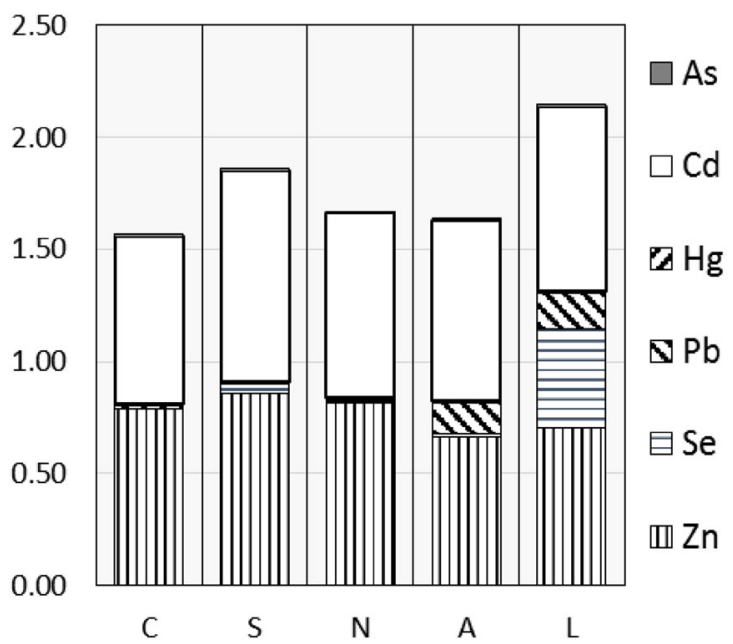

Fig. 4 Sum of extraction yield of $\mathrm{As}, \mathrm{Cd}, \mathrm{Hg}, \mathrm{Pb}, \mathrm{Se}$ and $\mathrm{Zn}$ in the five batch tests

\subsection{Becker tests}

Becker tests are characterised by a short duration $(1,3,5$ and $10 \mathrm{~min}$ ) compared with that of the reactor tests and by the high number of the washing repetitions until the final $\mathrm{pH}$ measured is practically equal to the initial value. The test is therefore very similar to what happens in column or in situ tests (continuous replacement of the leaching solution).

First, tests were carried out with four different leaching solutions at the same conditioning time of $5 \mathrm{~min}$ and $\mathrm{pH}=2$. The sum of the final extraction yield obtained is shown in Fig. 6.

It was observed that the extraction yield of $\mathrm{Cd}$ and $\mathrm{Zn}$ was always higher than that of other elements. Extraction yield of $\mathrm{Pb}$ was higher with $\mathrm{HCl}, \mathrm{HNO}_{3}$ and $\mathrm{CH}_{3} \mathrm{COOH}$ solutions, while it was high only with $\mathrm{H}_{2} \mathrm{SO}_{4}$ and $\mathrm{CH}_{3}$ $\mathrm{COOH}$ solutions in the case of Se.

Therefore, the best extraction yield could be achieved with acetic acid and it was decided to carry out a second series of tests at a variable $\mathrm{pH}(1.6,2.0,2.5,3.1$ and 4.0) and using different conditioning times of $1,3,5$ and $10 \mathrm{~min}$.

A total of 20 tests were carried out by using $5 \mathrm{pH}$ values at four conditioning times. The results were summarized using the final efficiencies obtained in each test (Fig. 7).

The values were distinct for analytes ( $\mathrm{As}, \mathrm{Cd}, \mathrm{Hg}, \mathrm{Pb}, \mathrm{Se}$ and $\mathrm{Zn}$ ), for $\mathrm{pH}$ (as indicated in the legend) and were sorted by decreasing times.

The data analysis shows how the analytical leachability decreases as the $\mathrm{pH}$ increases. Low or no leachability is obtained for:

- $\mathrm{Hg}$ at $\mathrm{pH}=1.6$ (see also Fig. 8a);

- $\mathrm{Hg}$ and As at $\mathrm{pH}=2.0$ (Fig. 8b); 

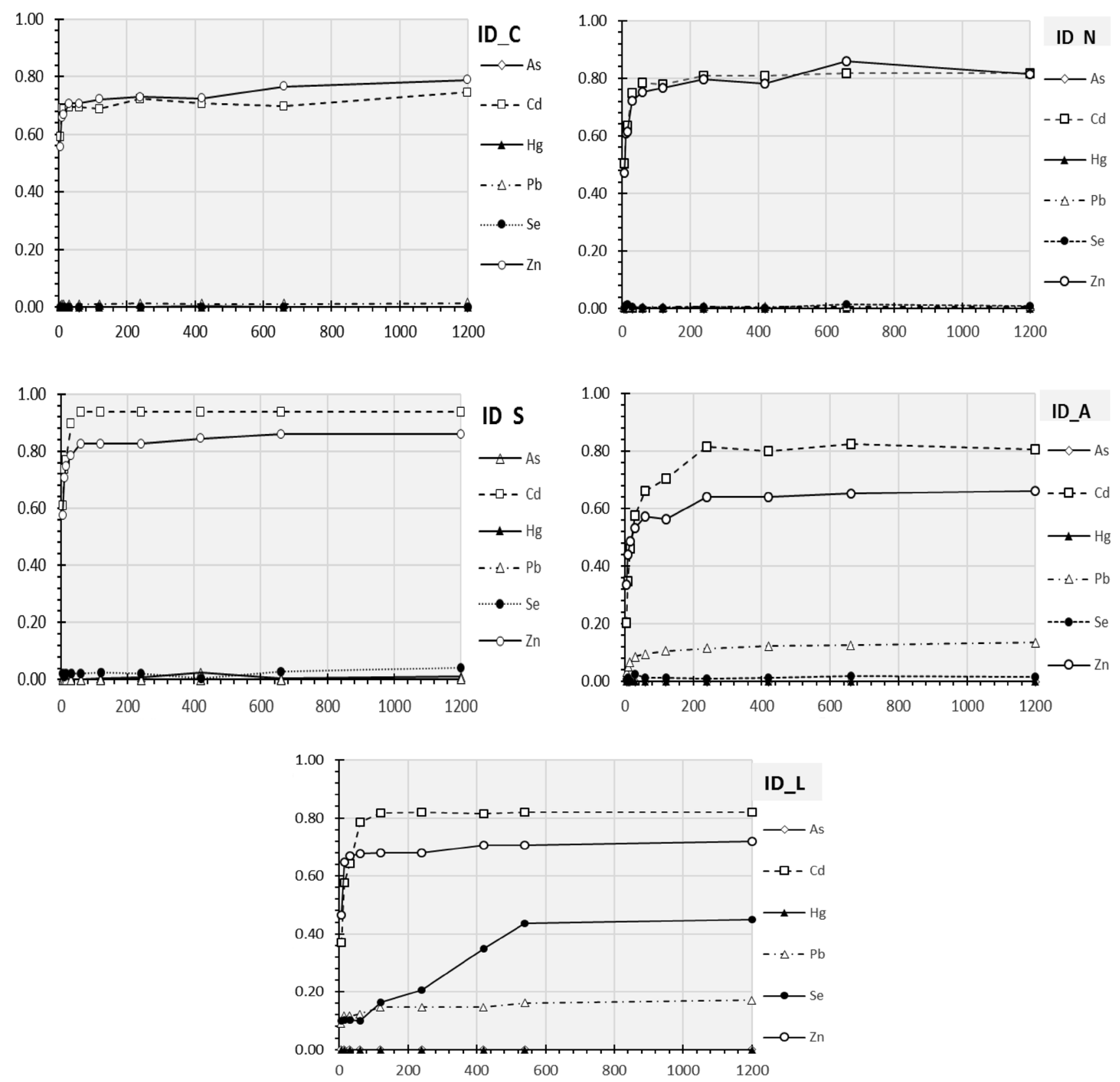

Fig. 5 Kinetics of the five batch-leaching tests: extraction yield versus time (min)

- $\mathrm{Hg}, \mathrm{As}$ and $\mathrm{Se}$ at $\mathrm{pH}=2.5$ (Fig. 8c).

For $\mathrm{pH}=3.1$ and 4.0 , the leachability of $\mathrm{Pb}, \mathrm{Zn}$ and $\mathrm{Cd}$ decreased slightly but remained higher when compared to other elements (Fig. 9).

Variable conditioning times between 1 and $10 \mathrm{~min}$ did not significantly affect the extraction yield. The kinetics showed that $t=10 \mathrm{~min}$ was the most representative of the extraction yield versus volumes of leaching solution used (liters).

The kinetics also showed how the increase in $\mathrm{pH}$ caused the reduction of leachability with the increase in time. The kinetics of $\mathrm{Cd}$ and $\mathrm{Zn}$ was always quicker and the required volume was $2 \mathrm{~L}$ except for $\mathrm{pH}=4$.

\subsection{Mercury leachability tests}

Batch and Becker tests revealed the challenges of leaching $\mathrm{Hg}$, whose concentration in eluate analysis was always $<0.10 \mu \mathrm{g} / \mathrm{L}$. This made it necessary to set up a new leaching procedure.

According to the literature (Abumaizar and Smith 1999; Klasson et al. 1997), potassium iodide (KI) with acetic acid 


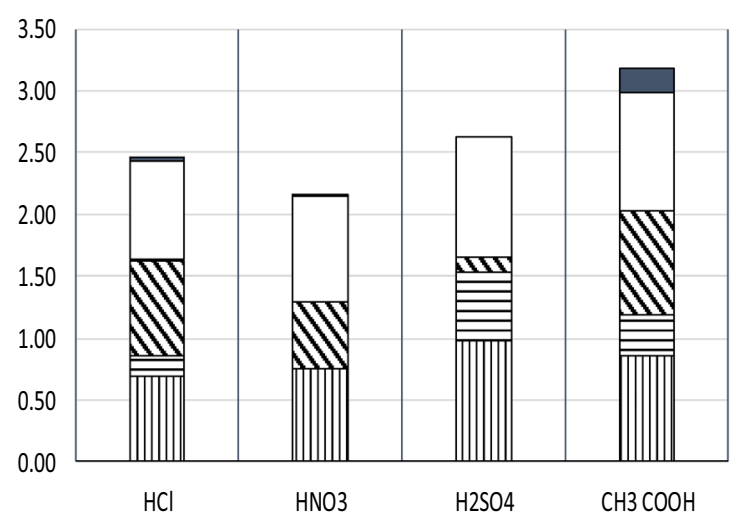

$\square \mathrm{As}$
$\square \mathrm{Cd}$
$4 \mathrm{Hg}$
$\mathbb{\mathrm { Pb }}$
$\mathrm{OSe}$
$\mathbb{\mathrm { Zn }}$

Fig. 6 Becker tests: sum of final extraction yield obtained in the preliminary tests

at a $\mathrm{pH}=2$ have been used as a solution with a molar ratio of 0.1 for KI.

Two tests were performed, with both $\mathrm{CH}_{3} \mathrm{COOH}$ and KI. First (Fig. 10), the use of the two reagents was at the same time, with a unique solution. In the second test (Fig. 11), only $\mathrm{CH}_{3} \mathrm{COOH}$ was used for the first seven washings, after which the KI solution was added and the next nine washings were performed.

The results of the first test showed good water-leachability of $\mathrm{Cd}, \mathrm{Zn}$ and, in particular, $\mathrm{Hg}$; but, a reduced water solubility of As and $\mathrm{Se}$ and especially of $\mathrm{Pb}$. On the contrary, the use of KI after the first seven washings significantly reduced this inhibitory effect.

\section{Summary of results}

Becker tests with repeated washings and different conditioning times are best suited to simulating real processes. These tests are easily repeatable under different conditions of the solution, $\mathrm{pH}$ and contact time. They represent the
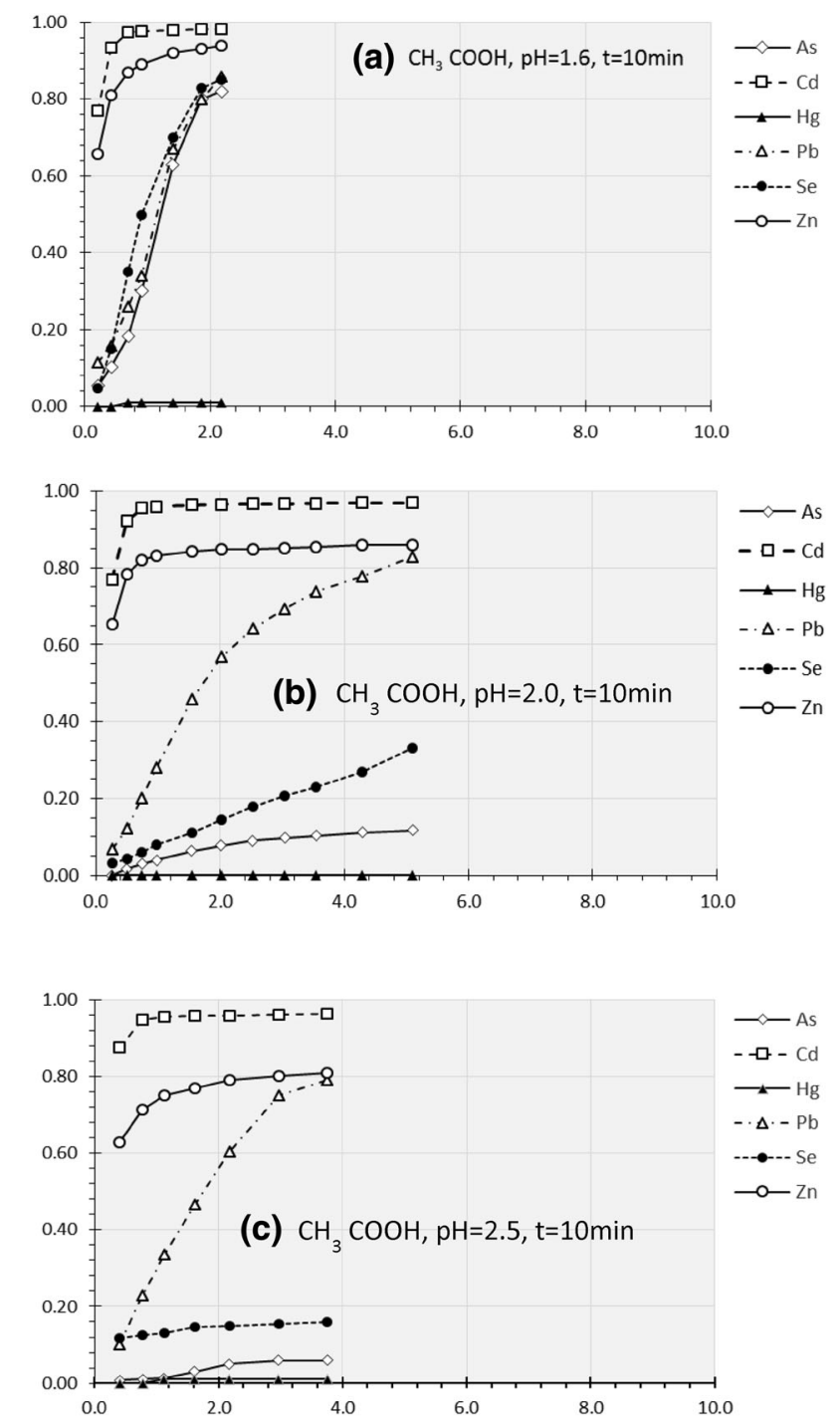

Fig. 8 Extraction yield versus volume (liters) for $\mathrm{t}=10 \mathrm{~min}$ and $\mathrm{pH}=1.6(\mathbf{a}) ; 2.0(\mathbf{b})$ and $2.5(\mathbf{c})$

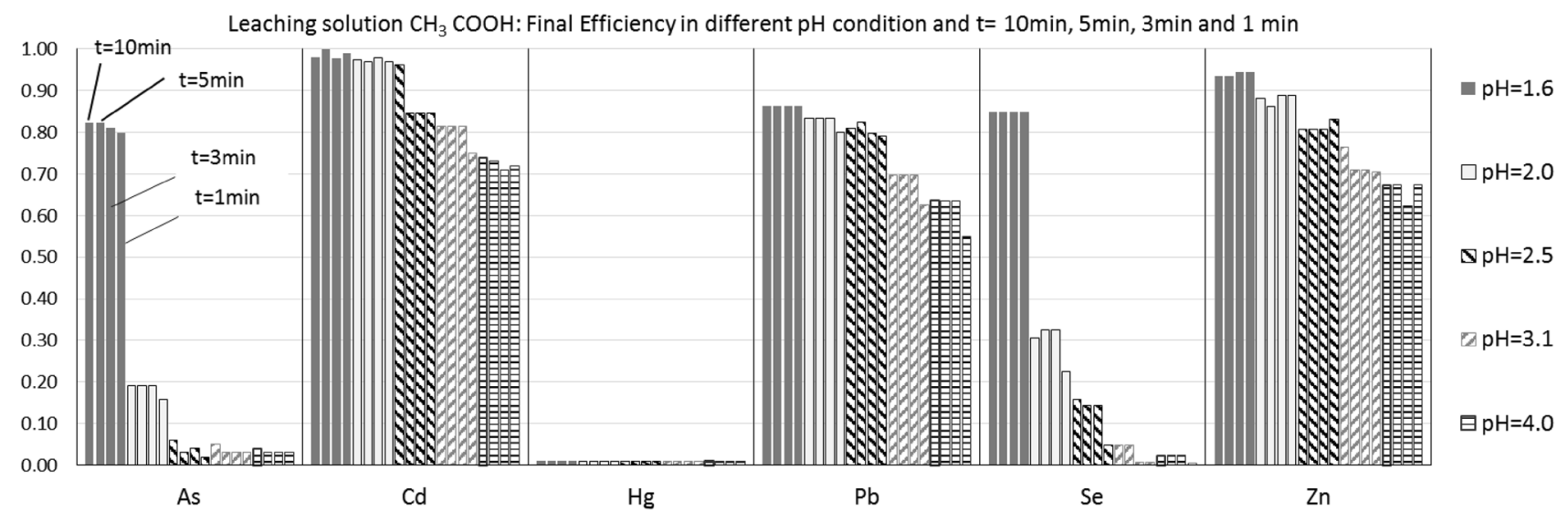

Fig. 7 Becker test: histograms of final extraction yield for $\mathrm{As}, \mathrm{Cd}, \mathrm{Hg}, \mathrm{Pb}, \mathrm{Se}$ and $\mathrm{Zn}$ with leaching solution $\mathrm{CH}_{3} \mathrm{COOH}$ in different $\mathrm{pH}$ conditions and for different conditioning times 

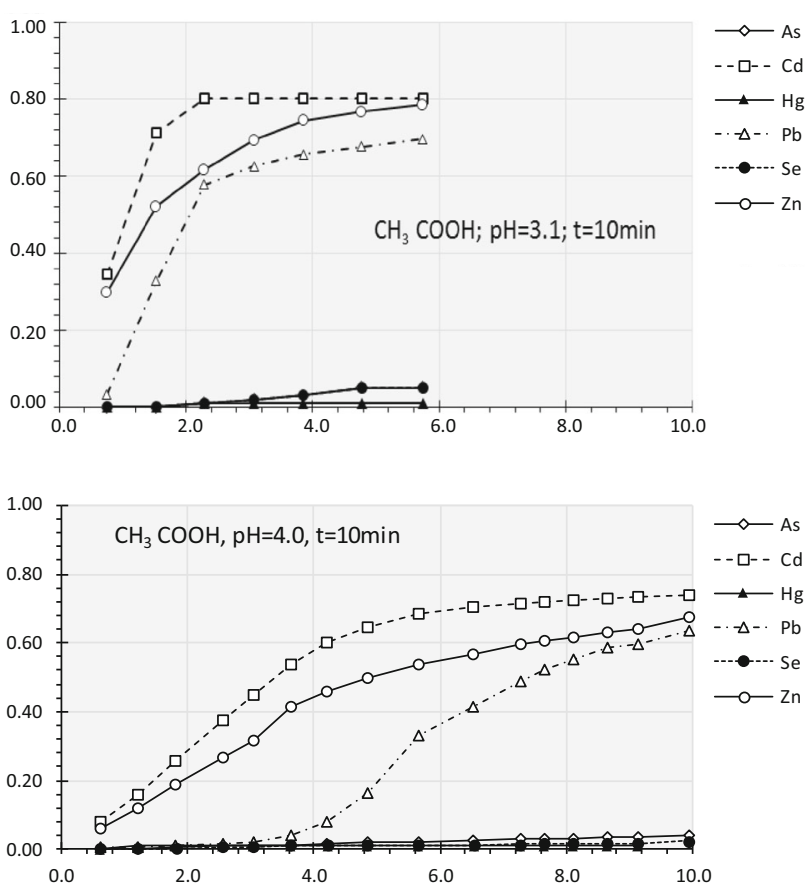

Fig. 9 Extraction yield versus volume (L) for $\mathrm{t}=10 \mathrm{~min}$ and $\mathrm{pH}=3.1$ and 4.0

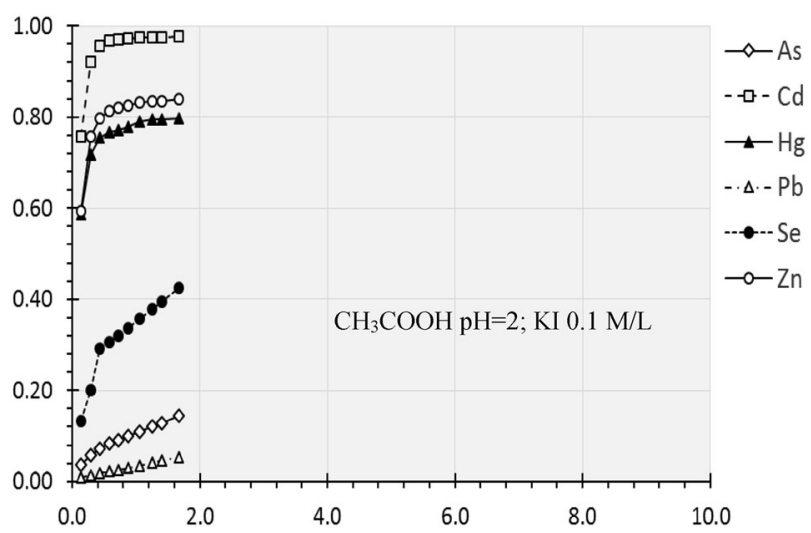

Fig. 10 Leachability of $\mathrm{Hg}$ : extraction yield versus volume (L), first test

exact process of soil washing and simulates the continuous replacement of the leaching solution most effectively that occurs in soil flushing.

Sequential extraction showed good leachability of $\mathrm{Zn}$, Cd (all extractable $>70 \%$ ); and poor leachability for As and $\mathrm{Hg}$.

Reactor tests (with hydrochloric, sulphuric, nitric and acetic acids) highlight good solubility of $\mathrm{Cd}$ and $\mathrm{Zn}$, poor solubility of As and $\mathrm{Hg}$, and good leachability of $\mathrm{Se}$ and $\mathrm{Pb}$ only with a particularly low $\mathrm{S} / \mathrm{L}$ ratio $(1 / 50)$.

Becker tests (with repeated washings and $\mathrm{CH}_{3} \mathrm{COOH}$ in the 4-1.6 pH range) always confirmed a good solubility of

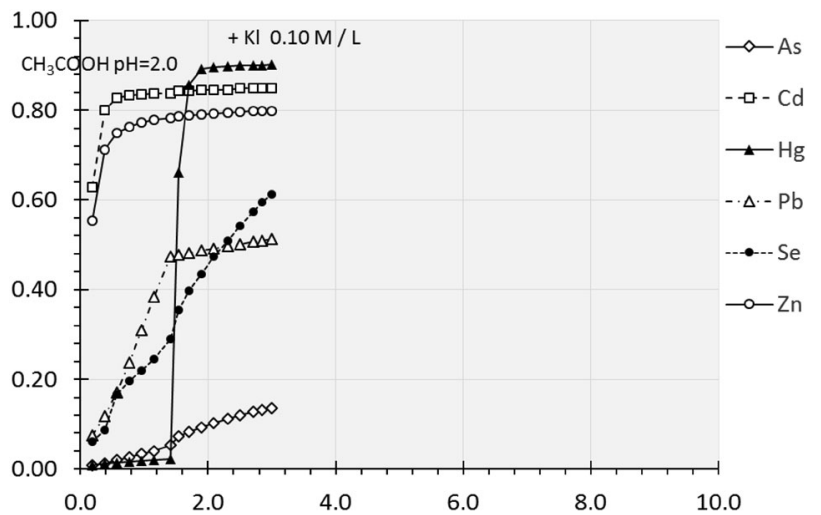

Fig. 11 Leachability of $\mathrm{Hg}$ : extraction yield versus volumes (L), second test

$\mathrm{Cd}$ and $\mathrm{Zn}$. Good leachability of $\mathrm{Pb}$ at $\mathrm{pH} \leq 2.5$ and a $\mathrm{pH}$ of 1.6 in the case of Se and As was observed. The nonleachability of $\mathrm{Hg}$ with $\mathrm{CH}_{3} \mathrm{COOH}, \mathrm{HCl}, \mathrm{H}_{2} \mathrm{SO}_{4}$ and $\mathrm{HNO}_{3}$ in the range of $\mathrm{pH}$ was also considered.

Becker tests (with repeated washings) using KI and $\mathrm{CH}_{3} \mathrm{COOH}$ and $\mathrm{pH}=2$ showed excellent $\mathrm{Hg}$ leachability and interesting results for other analytes. The presence of $\mathrm{KI}$ favors leachability, as well as $\mathrm{Hg}$, As and Se. Instead, it inhibits the leachability of $\mathrm{Pb}$ and $\mathrm{Cd}$.

The optimal result is obtained by using $\mathrm{KI}$ after leaching $\mathrm{Cd}, \mathrm{Zn}$ and $\mathrm{Pb}$ with only $\mathrm{CH}_{3} \mathrm{COOH}$.

\section{Conclusions}

We found that the six heavy metals viz. As, $\mathrm{Cd}, \mathrm{Hg}, \mathrm{Pb}, \mathrm{Se}$ and $\mathrm{Zn}$, in the investigated soil layer (between 1 and $4 \mathrm{~m}$ ) were all leachable but with different solutions, at different molar concentrations (or $\mathrm{pH}$ ) and with different volumes of leaching solution.

By using acetic acid solution, it was possible to obtain:

(1) Extraction of $\mathrm{Cd}$ and $\mathrm{Zn}$ with good results even under $\mathrm{pH}=4$;

(2) Good leachability of $\mathrm{Pb}$ at $\mathrm{pH} \leq 2.5$;

(3) Good leachability of Se and As at $\mathrm{pH}=1.6$.

However, leaching of $\mathrm{Hg}$ could not be achieved using acetic acid $\mathrm{pH}$ solutions in the range 4.0-1.6.

The use of potassium iodide solutions and $\mathrm{CH}_{3} \mathrm{COOH}$ at $\mathrm{pH}=2.0$ resulted in:

(1) Almost complete Hg leachability.

(2) Good leachability for As, $\mathrm{Cd}, \mathrm{Se}$ and $\mathrm{Zn}$, with the exception of $\mathrm{Pb}$.

(3) We showed that the optimal solution for leaching all the analytes present is the sequential use of two solutions $\left(\mathrm{CH}_{3} \mathrm{COOH}\right.$ and $\left.\mathrm{KI}\right)$. 
The application of washing processes that stop at reaching the remediation objectives and does not reach the maximum extraction yield obtainable can significantly reduce the volume of solution required.

Funding Funding was provided by Università di Cagliari.

Open Access This article is distributed under the terms of the Creative Commons Attribution 4.0 International License (http://crea tivecommons.org/licenses/by/4.0/), which permits unrestricted use, distribution, and reproduction in any medium, provided you give appropriate credit to the original author(s) and the source, provide a link to the Creative Commons license, and indicate if changes were made.

\section{References}

Abumaizar RJ, Smith EH (1999) Heavy metal contaminants removal by soil washing. J Hazard Mater B70:71-86

Desogus P, Manca PP, Orrù G (2013) Heavy metal leaching of contaminated soils from a metallurgical plant. Int J Min Reclam Environ 27(3):202-214

Di Palma L, Ferrantelli P, Medici F (2005) Heavy metals extraction from contaminated soil: recovery of the flushing solution. J Environ Manage 77(3):205-211

EPA (1991) In situ soil flushing, engineering bulletin 1991, EPA/540/ 2-91/021

EPA (1994) Method 245.1: determination of mercury in water by cold vapor atomic absorption spectrometry (CVAA)

Hashim MA, Mukhopadhyay S, Sahu JN, Sengupta B (2011) Remediation technologies for heavy metal contaminated groundwater. J Environ Manage 92(10):2355-2388
JCPDS 1985. International centre for diffraction data, powder diffraction file, Inorganic Phases; Printed in USA

Khan FI, Husain T, Hejazi R (2004) An overview and analysis of site remediation technologies. J Environ Manage 71:95-122

Klasson KT, Koran LJ Jr, Gates DD, Cameron PA (1997) Removal of mercury from solids using the potassium iodide/iodine leaching process. https://doi.org/10.2172/656449

Mann JM (1999) Full-scale and pilot-scale soil washing. J Hazard Mater 66:119-136

Mulligan CN, Yong RN, Gibbs BF (2001) Remediation technologies for metal contaminated soils and groundwater: an evaluation. Eng Geol 60:193-207

Navarro A, Martinez F (2010) The use of soil flushing to remediate metal contamination in a smelting slag dumping area: column and pilot-scale experiments. Eng Geol 115:16-27

Nemati K, Abu-Bakar NK, Abas MR, Sobhanzadeh E (2011) Speciation of heavy metals by modified BCR sequential extraction procedure in different depths of sediments from Sungai Buloh, Selangor, Malaysia. J Hazard Mater 192:402-410

Sahuquillo A, Rigol A, Rauret G (2003) Overview of the use of leaching/extraction tests for risk assessment of trace metals in contaminated soils and sediments. Trend Anal Chem 22:152-159

Svab M, Kubal M, Müllerova M, Raschman R (2009) Soil flushing by surfactant solution: pilot-scale demonstration of complete technology. J Hazard Mater 163:410-417

UNI EN 12506:2004 Caratterizzazione dei rifiuti-Analisi degli eluati-Determinazione di $\mathrm{pH}, \mathrm{As}, \mathrm{Ba}, \mathrm{Cd}, \mathrm{Cl}, \mathrm{Co}, \mathrm{Cr}, \mathrm{Cr}(\mathrm{VI})$, $\mathrm{Cu}, \mathrm{Mo}, \mathrm{Ni}, \mathrm{NO}_{2}, \mathrm{~Pb}, \mathrm{~S}$ totale, $\mathrm{SO}_{4}{ }^{2-}$, $\mathrm{V}$ e $\mathrm{Zn}$

U.S. Environmental Protection Agency (1999) Superfund innovative technology evaluation program-technology profiles, 10th edn. EPA-540-R-99-500a 